\title{
Knowing in translation practice
}

DOI:

10.1075/ts.6.1.08olo

\section{Document Version}

Accepted author manuscript

Link to publication record in Manchester Research Explorer

\section{Citation for published version (APA):}

Olohan, M. (2017). Knowing in translation practice: A practice-theoretical perspective. Translation Spaces(Netherland), 6(1), 159-180. https://doi.org/10.1075/ts.6.1.08olo

\section{Published in:}

Translation Spaces(Netherland)

\section{Citing this paper}

Please note that where the full-text provided on Manchester Research Explorer is the Author Accepted Manuscript or Proof version this may differ from the final Published version. If citing, it is advised that you check and use the publisher's definitive version.

\section{General rights}

Copyright and moral rights for the publications made accessible in the Research Explorer are retained by the authors and/or other copyright owners and it is a condition of accessing publications that users recognise and abide by the legal requirements associated with these rights.

\section{Takedown policy}

If you believe that this document breaches copyright please refer to the University of Manchester's Takedown Procedures [http://man.ac.uk/04Y6Bo] or contact uml.scholarlycommunications@manchester.ac.uk providing relevant details, so we can investigate your claim.

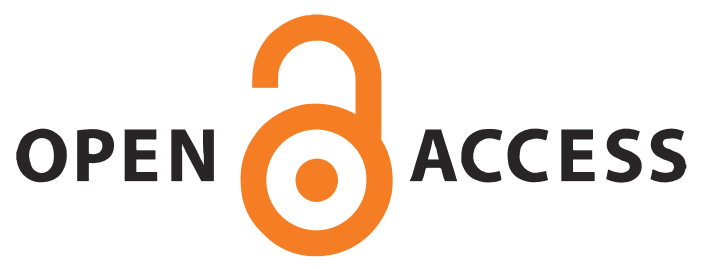




\section{Accepted Author Manuscript}

Olohan, Maeve (2017) 'Knowing in Translation Practice: A Practice-Theoretical Perspective', Translation Spaces 6(1): 160-181.

\section{Knowing in Translation Practice: A Practice-theoretical Perspective Maeve Olohan, University of Manchester}

Abstract:

This paper addresses the relationship between practice and knowledge in translation. It employs practice theory to conceptualize 'knowing-in-practice', introducing a theoretical approach to translation studies that enables an analytical focus on the practice of translating, rather than on the cognitive processes of translators or the textual features of translations. Against this practice-theoretical backdrop, knowing is construed as an emergent phenomenon that is sited in translation practice. Drawing on an empirical analysis of translating in a research organization, the paper then illustrates how this situated and embodied knowing is materially and discursively mediated and transpires in translation practice. Through its interdisciplinary approach, this research offers new sociological perspectives on the human and material interdependencies constituting translation in the workplace.

Keywords:

practice theory; knowing-in-practice; embedded knowing; embodied knowing; translation practice; workplace research

\section{Conceptualizing Practice and Knowledge}

Sociological scholarship of recent decades has seen a growth in research that addresses questions of how and why people do what they do, whether in everyday activities or professional settings. This interest in human practices per se is not a new phenomenon; philosophical roots of practice theory are found in works by Marx, Wittgenstein and Heidegger, with significant contributions also by Taylor, Bourdieu, Foucault and Giddens. Building on those foundations, prominent scholars in the second generation of practice thinkers, Ted Schatzki (1996; 2002) and Andreas Reckwitz (2002), provide the conceptual inspiration for many current applications of practice theory in numerous domains, from everyday practices in the home to practices within workplaces and organizations. Those studies address research questions of relevance for numerous academic disciplines, including organizational and management studies (Nicolini 2012), consumption studies (Warde 2005; 
Warde 2016), social anthropology (Shove, Pantzar, and Watson 2012), media studies (Bräuchler and Postill 2010) and political sciences (Jonas and Littig 2017). This paper constitutes a first application of this practice thinking to translation.

As noted above, Bourdieu $(1977 ; 1990)$ and Giddens $(1979 ; 1984)$ wrote about practices; however, neither can be said to have developed an ontological theory of practice. It is beyond the scope of this paper to offer detailed critique of Bourdieu's or Gidden's accounts of practices (see Schatzki 1996; Nicolini 2012; Shove et al. 2012; Caldwell 2012 for in-depth discussions) but it may be noted that Bourdieu $(1977 ; 1990)$ focused more on theorizing habitus and field than practice. Both scholars tended to neglect the role of non-human objects and materials in practices, and did not focus much attention on how social change can be accounted for in and through practices. As will be seen below, the theories of practice proposed by Schatzki and others owe some debt to Bourdieu and Giddens but also seek to address some of the perceived shortcomings in their work. Most sociological studies of translation thus far have drawn on Bourdieu's field theory, with a strong focus on translator habitus (Inghilleri 2005; Hanna 2016); the notion of practice, in the sense elaborated below, has not been placed centre stage in translation studies. ${ }^{1}$

This paper thus provides a conceptual framework for and empirical illustration of practicetheoretical research on translating practice and related practices. In particular, it uses practice theory to address the relationship between practice and knowledge in translation, conceptualized as 'knowing-in-practice'. Against the practice-theoretical backdrop, knowing is construed as an embedded and emergent phenomenon that is sited in translation practice. Drawing on an empirical analysis of professional practices in the translation department of a research organization, the paper then illustrates how this situated and embodied knowing transpires in translation practice, and sheds light on the materially and discursively mediated nature of that knowing-in-practice.

Section 1 introduces practice as the unit of analysis for this research, with reference to practice-theoretical work, particularly in sociology and organization studies. It then outlines a processual conceptualization of knowledge as embedded in specific contexts, inseparable from the knower and sustained by social interactions, termed knowing or knowing-inpractice. This contrasts with a conventional understanding of knowledge as an object that is codified and transmitted from one person and context to another.

In section 2, following an introduction to the fieldwork site and the methodology, a series of subsections draws on empirical data to produce an account of knowing in translation practice. A key aspect of this paper is that it relates those theories of knowledge, in particular knowing-in-practice (Nicolini 2009; Nicolini 2011; Nicolini 2012; Orr et al. 2016), to specific sites of translation practice, studying professionals in the workplace, rather than students in the classroom or translators under experimental conditions.

\footnotetext{
${ }^{1}$ Other socio-theoretical frameworks employed by a small number of translation scholars include Latour's actor-network theory (Buzelin 2006; Buzelin 2007), Luhmann's systems theory (Hermans 2007; Tyulenev 2012) and Gidden's structuration theory (van Rooyen 2013).
} 


\section{1. $\quad$ Practice Theory}

Comprehensive accounts of practice theory may be accessed elsewhere (e.g., Nicolini 2012; Bain and Mueller 2016); this section introduces the concepts that are most pertinent for this study, by explaining what is typically meant by practices and practice theory, as a precursor to the analysis of the role of knowledge in translation practices.

It is important to note from the outset that practice theory is not a unified theory; there are numerous approaches to the study of practices but they share a focus on the field of practice in their investigations of agency, knowledge, power, science and other aspects of human activity (Schatzki 2001, 13). Practices may be understood as "embodied, materially mediated arrays of human activity centrally organized around shared practical understandings" (Schatzki 2001, 3).

While scholars use a variety of terms and may focus on various components of practices, we may note, firstly, that the embodied nature of practices is key to practice theorists, as shown in Postill's $(2010,11)$ description of practice theory as a "body of work about the work of the body". Moreover, practice theory pays attention to the nonhuman objects and materials that participate in practices; hence the emphasis in the above definition on human activity as materially mediated. A shared understanding is also key to a practice being recognized as such; as defined by Reckwitz $(2002,250)$, a practice is "a routinized way in which bodies are moved, objects are handled, subjects are treated, things are described and the world is understood". In a similar but streamlined account, Shove et al. (2012) regard practices as comprising materials (i.e. things, tools and the body), meanings (i.e. mental activities, emotions and motivations) and competences (i.e. understandings, skills and know-how). Finally, Schatzki's $(1996,89)$ description of practice as "a temporally unfolding and spatially dispersed nexus of doings and sayings" highlights an interest, not only in the performance of bodily actions in particular places and points in time, but also in discursive performances or representations.

Research taking a practice approach tends to address questions about the types of practice that are prevalent, how those practices develop, how they are combined, how they change, and how practices affect other practices (Schatzki, Knorr-Cetina, and Savigny 2001). In most accounts of practice, there is a tendency for the human aspect of activities to be foregrounded; people are conceived as "carriers" of practices (Reckwitz 2002). ${ }^{2}$ Practiceoriented research may therefore also consider how individuals position themselves within practices, how people understand practices and their roles within those practices (Warde $2005,149)$. Other theoretical work focuses on how practices are organized into bundles, complexes or constellations (Schatzki 2005; Shove, Pantzar, and Watson 2012) or on how different types of practices may be distinguished, e.g. dispersed and integrative (Schatzki 1996) or compound practices (Warde 2016). Our attention, for the remainder of this paper, is on the relationship between knowledge and practice in the workplace.

\footnotetext{
2 This contrasts with posthumanist practice orientations, e.g. Latour's (2005) actor-network theory (ANT), which is characterized by the principle of symmetry between non-human and human actors.
} 


\subsection{Knowing-in-Practice}

Having introduced key practice-theoretical concepts above, we now focus on how knowledge can be understood in relation to practices. There are many diverse understandings of what constitutes knowledge, and many categorizations of forms or kinds of knowledge, perhaps starting from the Aristotelian notion of knowledge as a fusion of epistêmê, technê and phronêsis. ${ }^{3}$ Key current trends in theories of knowledge are structured around divergences between knowledge as a product and knowledge as a process (Tooman, Akinci and Davies 2016).

Conceived as a product or object, knowledge is akin to an information package that is codified, can be acquired, possessed and used by an individual, and transmitted from a knower to others in different contexts. This generalizable knowledge would pre-exist the practices or contexts in which it might be used. Cook and Brown $(1999,382)$ refer to this conception of knowledge as an "epistemology of possession".

In organization studies, particularly when informed by practice theory, there has been a shift away from thinking about knowledge as the possession of individuals to considering knowledge in use (Rennstam and Ashcraft 2014, 5). This second perspective views knowledge as situated in specific contexts of time and place in which knowers operate (Tsoukas 2005; Tooman, Akinci, and Davies 2016, 19). Knowledge is construed as dynamically and socially produced, shared and legitimated. It is not readily separable from the knower and their interactions with people and other elements within a system or web of interdependencies, and is therefore more aptly referred to as knowledge in practice, knowing or knowing-in-practice. In this regard, Cook and Brown $(1999,383)$ talk about knowledge as action, and an "epistemology of practice".

These different perspectives on knowledge reflect and inform understandings of the relationship between knowledge and practice (Nutley et al. 2016; Nicolini 2011). At one end of the scale, knowledge and practice may be seen as rather separate phenomena and the relationship between them may be linear, but also problematic, as exemplified by discussions of incompatibilities between theory and practice, which are also familiar within translation studies. At the other end is a view that knowing and doing are inseparably entangled; in Nicolini's (2011) "radical" terms, knowing transpires in and through sociomaterial practices.

Between these two positions are variations in thinking about the knowledge-practice relationship. Cook and Brown (1999, 394), for example, describe knowledge (possessed) and knowing (as part of action) as two distinct entities and look at the way they interact in work practices in a "generative dance" that produces new knowledge and new ways of knowing. Other conceptualizations of the knowledge-practice relationship focus on shared knowledge as an asset of communities or networks of practice (Lave and Wenger 1991; Brown and Duguid 1991). This paper draws on the work of Nicolini (2011), Gherardi (2006), Orlikowski (2002) and others to focus, not on the community of practice but rather on the "practices of a

\footnotetext{
${ }^{3}$ Note that translations of these terms are often shaped by contemporary distinctions between theory and practice and modern conceptions of science (Parry 2014).
} 
community", with particular emphasis on the contextual enactment of practices and of knowing-in-practice (Gherardi 2009, 121).

A conceptualizing shift from knowledge as product/possession to knowing in practice is not synonymous with a shift of attention from explicit knowledge to tacit knowledge, or from know that to know how, or from declarative to procedural knowledge. It is rather a reconceptualization of the nature of knowledge and how it is created and shared; knowledge is something people do rather than something people have (Blackler 1995, 1022).

Taxonomies of knowledge, such as the enduring explicit/tacit distinction, are useful but also potentially problematic if treated as different forms of knowledge, or as forms that can be readily converted from one into another (Nonaka 1994). The seminal work on tacit knowledge by Polanyi $(1962 ; 1966)$ examined the personal knowledge tied to bodily and social experiences that may not be articulable, but Polanyi treated both explicit and tacit as dimensions of knowledge rather than different forms. Other scholars (Tsoukas 1996) also argue for this more integrated approach. Blackler (1995) reviews previous research that describes knowledge as embrained, embodied, encultured, embedded or encoded, but cautions against the simplification inherent in such typologies, highlighting how knowledge is multifaceted and complex in that it can be "both situated and abstract, implicit and explicit, distributed and individual, physical and mental, developing and static, verbal and encoded" (Blackler 1995, 1033).

In recasting knowledge, or knowing, in practice terms, and formulating a research agenda, Blackler $(1995,1041)$ finds it useful to focus on characteristics of knowledge in practice, i.e. knowledge as mediated, situated, provisional, pragmatic and contested. Later work by Nicolini $(2011,605)$ similarly characterizes organizational knowing as processual, emergent, relational, dependent on connections in place and time, embodied, provisional, contestable, and mediated through specific discursive and material conditions and artefacts. It is these characteristics of knowing in translation practice that are investigated in this paper.

\subsection{Knowledge and Knowing in Translation Studies}

In translation studies, debates about the usefulness of theory for practice (Chesterman and Wagner 2002) tend to reflect a traditional conceptualization of knowledge, as possessed by the individual, and, often, also a linear view of the relationship between knowledge and practice, whereby knowledge is acquired to be applied (or not) in practice. Some research has used surveys to identify the knowledge and skills base to be acquired by student translators (Lafeber 2012), while other contributions develop cognitive models of competence and elaborate the nature of specific competences and sub-competences, including, for example, acquisition of declarative knowledge (PACTE 2014). As in many other domains, translation theorizing and pedagogy have tended to concentrate on embrained and encoded knowledge (of languages, terminology, specialized domains) rather than the embodied, embedded or materially mediated knowing that is explored in this paper.

Although based on theories of situated and extended cognition rather than practice theory, Risku's (2010) and Risku and Windhager's (2013) papers are among the few previous theoretical contributions to conceptualize translation activity as situated and embodied. Some 
understanding of the embeddedness of knowledge is also reflected in approaches to situated learning in translation pedagogy, following on from Kiraly's (2000) introduction of social constructivism to translation pedagogy and his later work on a "fractal view" and a "holisticexperiential" approach to pedagogy (Kiraly 2012). Situated learning is described as helping learners to make the transition from the classroom community of practice to a professional community of practice by "reproduc[ing] the professional context" for the learner using various pedagogical methods, activities and tasks (González and Enríquez 2016). By situating learning in this way, emphasis is placed on embedded and, to some extent, emergent knowledge, with deeper consideration of interpersonal experiences, thus shifting some attention away from encoded and embrained knowledge. However, there remains scope to accommodate other dimensions of knowing that are inherent in translation practices but are seldom addressed in pedagogy or theory, namely embodied knowing and materially mediated knowing.

One of the few previous theorizations of the relationship between knowledge and translation is offered by Risku (2013) and Risku, Dickinson \& Pircher(2010). Establishing translation as a form of knowledge work, these contributions draw on the knowledge management literature and on distinctions between tacit and explicit knowledge to produce a typology of different types of knowledge for translation. Codifiable and non-codifiable knowledge is listed for each type and consideration is given to the kinds of tools or instruments available to translators to help them to develop and use both codifiable and non-codifiable knowledge. The explicit knowledge is largely characterized as encoded and accessed in databases, manuals, translation memories, etc. By contrast, most of the tools and instruments enabling non-codifiable knowledge to be developed are interactional in nature, e.g. asking others for advice, interacting with others in physical or virtual settings, participating in conferences or workshops.

Despite this welcome attention to embedded and relational knowing, there are a few key differences between Risku's discussion of knowledge management and the conceptualizations on which this paper is based. Firstly, as discussed in the next section, I proceed on the assumption that all work is knowledgeable, not just what is termed 'knowledge work'. Secondly, a practice-theoretical approach seeks to move away from the notions of knowledge acquisition and knowledge management and towards knowing as emergent. Against that backdrop, I consider knowing to be socially embedded and relational, so that it is not only tacit or non-codified knowledge that transpires through social interaction. Finally, this paper empirically investigates knowing in a specific sited practice of translation. In that regard, it also contributes to a nascent but growing body of workplace research conducted in commercial translation settings (e.g. Risku 2009; Risku et al. 2013; LeBlanc 2013; Ehrensberger-Dow 2014; Olohan and Davitti 2015; Ehrensberger-Dow and O’Brien 2015).

\section{A Study of Knowing in and through Translation Practice}

In studying knowledge in relation to work, most sociological attention has been paid thus far to 'knowledge workers' in the 'knowledge economy' of Western, post-capitalist societies. 
Studies have tended to focus on a small number of professions deemed to be (or claiming to be) knowledge-intensive and engaged in complex problem-solving (Rennstam and Ashcraft 2014). However, increasingly scholars call for a practice-based approach that see all work as knowledgeable (Blackler 1995; Thompson, Warhurst, and Callaghan 2001) and that addresses questions about the nature and role of knowledge as it evolves in everyday work of all kinds. Despite this call, Rennstam and Ashcraft $(2014,12)$ highlight ongoing biases in research that tend to favour masculinized, technical and scientific fields and professions as the archetypes of knowledge-intensive work, to the neglect of other occupations, leading to a recentring on certain, elite practitioners and consequently a "highly partial understanding of knowledge in use". This point is important in the context of this paper; translation is a professional activity dominated by women, whose knowing-in-practice has not been studied explicitly to date. Through this study we can therefore hope to begin to redress those scholarly balances.

If we understand knowing as transpiring in and through sociomaterial practices, then studying knowing in practice requires us to study the "real-time accomplishment of a specific sited practice" (Nicolini 2011, 605). The analysis of knowledge and translation practices that follows emerges from my observations of translators at work in a specific site, detailed below. It is based on a thematic coding and analysis of field notes and artefacts, and it is informed by theoretical, practice-oriented frameworks of knowledge and knowing, as outlined above, and previous empirical studies of knowing in other workplace practices, including telemonitoring in hospitals, (Nicolini 2011), product development (Orlikowski 2002) and engineering (Reich et al. 2015).

The aim of this analysis is to show how knowing and practice are entangled in the translation workplace. In addressing a translation studies readership, I do not produce the thick, multivocal description typical of an ethnographic narrative or a praxiography, which would, in any case, exceed space limitations. Instead, my analysis informs a more generalized account of how knowing transpires in translation practice, illustrating, firstly, how knowing emerges as embedded and embodied, materially and discursively mediated, and secondly, how practice-oriented conceptualizations are relevant and applicable to translation. The subsections focus on different characteristics of knowing-in-practice for analytical expediency, but it should be stressed that knowing-in-practice is often all of these at once.

\subsection{The Site of Translation Practice}

My fieldwork took place in the translation department of a large research organization. The research organization (henceforth $\mathrm{RO}$ ) is divided into numerous institutes and units for different scientific and technological specializations (not specified here to preserve anonymity). By contrast with other parts of the RO, the translation department is very small, comprising three translators, for whom I use pseudonyms Anna, Barbara and Caroline, and an administrative coordinator, Diane. The translation department provides translation and editing services to members of the RO, working principally between English and Language $\mathrm{A}$, the official language of the country in which the RO is situated. One of the three translators, Anna, is the translation department team leader. My access to the site was 
facilitated by approaching Anna, who secured approval for the research from her superiors and disseminated information about the project to her colleagues, the prospective participants. Following procedures for gaining ethical approval from my university and consent from all participants, I spent time in the translation department observing the four members as they worked. I also participated in team meetings and interacted with members more informally away from their desks, for example, in lunch breaks.

A large proportion of the translators' time is spent translating documents from Language A to English, with a much smaller proportion consisting of translation in the opposite direction. All translation done by any of the translators is subsequently checked by one of their two colleagues. I use the term 'revising' (British Standards Institution 2015) for this activity.

In addition to translating and revising, the translators also work as English-language editors, editing texts which have been drafted in English by researchers in the RO, identifying and repairing various deficiencies, with the aim of producing the standard of academic English required or expected by the gatekeepers of international scientific publishing.

\subsection{Knowing as Situated in Time and Place}

The translators, Anna, Barbara and Caroline, have varying numbers of years of experience in the RO but they all translate and they all 'know translating'. In practice-theoretical terms, they are the carriers of the practice of translating in the RO. This practice comprises sets of their activities (and activities of others), organized around shared practical understandings and mediated through bodily actions and interactions with material objects. Translating is recognized as a practice within the $\mathrm{RO}$ and is reproduced in a more or less stable way in the department, while also undergoing adaptations over time, as human activities, materials and practical understandings also change.

As discussed above, knowing in practice is "a situated knowing constituted by a person acting in a particular setting and engaging aspects of the self, the body, and the physical and social worlds" (Orlikowski 2002, 252). The aim for empirical research is to study how "the knower and what is known emerge together in practice" (Nicolini 2011, 605). To illustrate the emergence and situatedness of this knowing in practice, let us consider the range of materials that the translators translate. On the one hand, these are extremely specialized texts performing expert-to-expert communication with an external readership, e.g. scientific research articles and research funding applications. However, the translators also translate texts that enable communication between the RO and the general public, such as newsletters, magazines, websites and annual reports. In addition, they translate documents relating to the administration and management of the RO that are circulated internally for specific readership groups, e.g. strategy and planning documents, contracts and staff training materials. Other texts translated regularly for internal consumption by members of the RO include the daily canteen menu, staff newsletters and intranet news posts.

In their practice the translators enact an understanding of many of the complex ideas and concepts being communicated through the material they translate. They are also familiar with much of the terminology used in the RO to designate those concepts in English and language 
A. This is evident, for example, when they read and produce a translation of specialized discourse without recourse to reference material, or when they use relevant reference resources efficiently to retrieve conceptual explanations or terminological equivalents. Both of these activities are observed as recurrent in their practice. Their use of internet search strategies is fast and efficient, enacting specific practice-related knowing, for example in deciding what alternatives to use as search terms, or in knowing how Google handles certain scientific nomenclature or formulae.

The translators also reproduce in their translations the conventions of a wide range of genres such as those mentioned above, often without needing to expend much time or cognitive resources deliberating on what those genres might look like. As with concepts and terms, they also know where to find exemplars of specific scientific genres when required, and they retrieve these quickly when needed. As Anna, Barbara or Caroline start working on a new translation, they relate it to an institute and activity in the RO with which they are familiar and they consult previous publications from the same area. In addition, their actions of retrieving relevant reference documents from other ROs show that their knowing about research activities extends to the wider scientific research fields beyond their RO; they also know about the networks and collaborations between their RO and external organizations and they enact this knowing in their retrieval of relevant reference material.

Thus, the translators, not formally educated in scientific specializations, nonetheless know about the various branches of science and technology studied at the RO, and about other specialist areas, like financial, personnel or strategic management. This knowing transpires primarily through their practice of translating documents pertaining to those subjects in this context. This theoretical and abstract knowledge may be regarded as embrained. However, Anna, Barbara and Caroline do not learn about a technical subject in a context-independent way but rather predominantly in relation to the work done by their RO as it participates in national and international research fields and as it discursively constructs and communicates its research. Their knowing not only transpires through their translation practice but also shapes and structures their practice, as was observed in their conceptual and terminological research strategies and activities.

The physical and temporal co-location of the translators and the scientists, administrators and other authors of the source texts, as well as the readers of many of the translations, is also highly relevant to their translation practice and their knowing. One illustration is Caroline's participation in a tour of one of the research areas of the RO one lunchtime. On the tour, she sees and interacts with the materials and people engaged in that research practice, and hears a discursive account of the research, as constructed by a representative of this research area in the RO. Thus her knowing about that technical work also emerges through her recent embodied experience of it.

The situatedness of practice and of knowing is not confined to specialized scientific aspects of the translators' activities. Another example to consider is that the translators sometimes eat in the canteen whose menus they have translated. They therefore see and taste the food, including the national and regional specialities for which they have coined names or descriptions in English. They are familiar with how the menus are posted in language A and 
English on the RO's intranet, enabling people to decide whether to go to the canteen that day, or what to choose for lunch. They experience how the dish labels are displayed on or above the serving stations. They know that the English translations are for international employees and visitors to the RO; these are people who they encounter in the serving areas or the queues, or consuming the food at tables next to them. Their knowing how to translate the menus can therefore be seen as embedded but also embodied and materially mediated.

\subsection{Knowing in Regimes of Doings and Sayings}

Borrowing from Nicolini's $(2011,610)$ description of other practices, we can say that knowing how to translate transpires through Anna, Barbara and Caroline's "tuning in and contributing to an existing regime of doings and sayings". From my perspective as an observer, the regime of existing doings and sayings is vast, with some doings and sayings specific to the members of the translation department, and others related to the RO as a whole or other administrative units in which the department is organized. Here I discuss just a small number of examples, related to one particular aspect, namely the temporal organizing of work practices.

The translators use their identity cards to swipe in and out of work as they enter or leave their building. This builds up an institutional record of time spent at work, from which overtime is calculated. A topic of conversation during my visit is how Anna will manage to take the free days that she has accumulated from many hours of overtime, something that is quite difficult for such a small team to manage, especially during the summer holiday period. The translators then proceed to the area of the building in which their department is located. Here they also check in, in a more informal and collegial sense, by going to greet any colleagues who are already in their offices; they also check out by saying goodbye at the end of the day. During the day, the time spent on a specific job is recorded, as the translator logs into and out of jobs on her computer. This action produces electronic records of jobs and time taken; each translator can access their personal record at any time, showing their cumulative work statistics for the year, month or day, and a breakdown of jobs by time, task, commissioning RO section, etc. These are just some of the doings and sayings that form part of the regime of working in the translation department; the translators' participation in them constitutes one aspect of their knowing in relation to how working time is organized and managed, both institutionally and among their colleagues.

On arrival in the morning, a first port of call is often Diane's office, which functions as a work hub and a social hub. It contains a drinks station, and throughout the day Anna, Barbara or Caroline go there to prepare drinks to take with them to their offices. At times, their paths will cross, giving an opportunity for work-related or non-work related chat, and interaction with Diane who is often working at her desk in the same room.

However, the function of this space as a work hub is also salient. Through Diane's coordinating and administrative work, the translators' new assignments are made available here, in physical form, for them to pick up and take back to their offices to complete. The assignments are stacked in an desk tray, in plastic folders containing, in hard copy, the source text to be translated with accompanying identifying documentation relating to the assignment, 
the client, deadlines, etc. When they have finished a job, the translators deposit the plastic folder, now also including the translation, in an adjacent tray. The trays are clearly labelled to indicate which are the assignments awaiting translation and which are the completed ones. These are further examples of where the translators enact their knowing of existing regimes of doings and sayings. Diane's practice of project management by which this coordinating and record-keeping work is done is an interconnected practice (addressed also in 2.7 below). Her knowing, transpiring through her project-managing practice, is intertwined with the knowing of the translators.

The coordination of translation assignments is a joint effort between translators and Diane. At the start of each week, all four hold a planning meeting to go through a rolling schedule of ongoing and upcoming assignments which Diane provides in hard copy for each team member. The list is updated by Diane in preparation for this meeting but also during the intervening week. The list contains one-off assignments but also indications of regular assignments that materialize in accordance with institutionally defined timetables (e.g. fortnightly or quarterly newsletters or the annual report). The knowing in practice transpires in their joint coordinating and planning efforts to set up an achievable schedule, moving and negotiating tasks when necessary. The existing regime of sayings is in evidence on the schedule, for example, through the use of many abbreviations for institutes and units of the RO and pre-defined labels for text genres. Likewise, the names of clients or commissioners evoke shared understandings for the team, for example, in the knowledge that one is a stickler for deadlines, while another is likely to deliver their source text late.

The translators and Diane seek to allocate translation time by balancing ongoing large assignments that may take several weeks, e.g. the annual report, alongside smaller ones that come in with much tighter deadlines. Most assignments on the schedule are assigned a translator and often also a reviser, though some less urgent ones remain unassigned at this point. When all three translators have extremely busy schedules, which is most of the time, and particularly if one of them has upcoming leave, they need to know which tasks to prioritize or which deadlines might be negotiable. This knowing is based on prior experience and their relations with the commissioners or other units, as well as their familiarity with the activities and needs of those other units. Allocations or reallocations are discussed, negotiated and agreed at the meeting; this also relies on familiarity with their colleagues' strengths, preferences, past assignments, ability to juggle tasks, and other knowings. The schedule and its daily updates thereby enact the dynamic processes of serving clients and mutually managing workloads.

These snapshots of some of the scheduling and organizing of work serve as examples of the regimes of doings and sayings in which the translators participate and which mutually constitute their knowing and their translation practice. The translators' knowing in translation practice transpires, not only in and through their work at their desk translating the text but also in and through these kinds of organizing activities, which are embodied but also discursively and materially mediated. 


\subsection{Knowing as Materially Mediated}

As seen above, knowing transpires in and from the physical actions of the translators.

However, knowing also transpires in and from the mediatory work of various objects and the translators' use of them in practice. Examples of how materials mediate the practice and the knowing are seen in the description above of how translation assignments are physically organized in folders, placed in certain locations, picked up, opened, closed, dropped off, filed, etc.

Other examples of material configurations participating in and constituting the translation practice in the RO can be observed in the translators' offices. Each translator has a main desk equipped with a computer and two monitors, as well as other work surfaces and many material objects. Translating is done at their main desk, and the material configuration of their computer equipment is actively involved in this practice of translating. Each translator uses one monitor for their translation memory (TM) software; here they see the source text and the editing interface for inputting their translation and they have access to functions of the TM, e.g. segment matches, term retrieval or concordancing. They use the other monitor for consulting reference material and carrying out research to help them to solve problems they encounter while translating. The practice of translating involves moving their attention between these two monitors, with sustained work in the TM interrupted by bursts of research activity on the other monitor. The knowing that transpires through these mediatory artefacts relates to effectiveness of researching and translating in this way and the ability to switch, bodily and mentally, between tasks. This material configuration is shared by the three translators and can also be seen as part of the existing regime of doings - a new translator joining the team would be given similar equipment, set up in similar fashion.

TM software is used by the translators for almost all jobs. One of its mediating functions is evident in that it provides the user interface through which the source text is viewed and the target text is entered. Its main functions, to retrieve fuzzy matches and terms from previously translated work, and to allow translated segments to be stored for future retrieval, also clearly mediate the knowing-in-practice. However, the TM's mediating function in translation practice extends beyond those core functions. Even when segments are not matched in the TM and terms are not in the termbase, the translators' knowing in practice is mediated through other functions, such as the AutoSuggest dictionary (a proprietary function that suggests words and phrases as the translator types). Here, the textual material held in the TM (generated from previous translation work) is organized by the software's algorithms to provide fragmentary, contextual suggestions; these suggestions appear visually on screen in drop-down menus as the translators type. The translators manually manipulate their mouse or keyboard to move through the AutoSuggest options and choose the most appropriate one, which then appears at that point in their translation. The availability of these suggestions is something that, in turn, shapes their translation practice, for example, by providing a convenient alternative to terminology look-up and prompting them to reduce the time they spend managing their terminology in termbases. 


\subsection{Knowing as Embodied}

The examples above show how 'knowing translating' transpires in and through a combination of bodily and discursive activities that constitute the practice. Indeed, much of the embrained work of translation is facilitated by discernible bodily activity and movement, e.g. embodied knowing can be observed in the ways in which translators interact with their workplace equipment when they translate. For example, as might be expected, they constantly use mouse and keyboard as input devices. In performing recurrent functions within her TM software, I observe that Caroline favours keystroke combinations over mouse movements and clicks, increasing her speed of movement through her text. These habitual, coordinated finger and hand movements are, of course, common to regular users of keyboards and mice but are also part of the knowing that transpires in translation practice, where software-specific keyboard shortcuts can become an integral aspect of working with a TM. Likewise, the shifting of attention between the translators' two monitors, as they switch from one activity to another, inevitably involves movements of eyes, heads and other parts of the body. Other examples of knowing embodied in practice can be observed in the physical behaviour of translators as they think and concentrate, whether we observe Anna turning her head so that she can look out of her window while thinking, or Barbara's movement forwards and backwards in her chair as she reads reference material, or the tapping of her fingers on her mouse as she deliberates about the appropriateness of a translation solution.

Not all of the translators' physical movement takes place at their desks. As noted above, movement within the department, between offices and within the space of Diane's office, is integral to the translation practice in the RO. However, the physical activities are not confined to the department. For example, Caroline goes to the library in another section of the building to consult some reference material, and Barbara takes a walk around the RO's grounds during lunchtime, hoping that this will improve her concentration for a challenging task awaiting her in the afternoon. Caroline finds it cognitively and physically conducive to her work if she cycles there in the morning, particularly if she takes the scenic route. Barbara uses a standing desk for certain revising activities to avoid back ache. All of these activities involve the body and mind, but also material objects - books on shelves, the landscaped grounds of the RO, a bicycle, countryside or a standing desk, to name just some of them. Traditionally in translation scholarship, these kinds of physical actions, non-human materials and the interactions between them would be invisible, unseen, disregarded or dismissed as irrelevant to the study of translation. However, these workplace observations show that they participate in the practice and in the knowing-in-practice at this site. As argued by Brown, Greig and Ferraro $(2016,86)$, "if knowing emerges from practice, through participation in the activities at hand, then the whole body must be engaged, from tongue to toe, and gut to heart". Likewise, it can be argued that the material objects with which the body engages must also participate in and shape the practice and the knowing-in-practice.

\subsection{Knowing as Relational}

According to Gherardi, "to know is to be able to participate with the requisite competence in the complex web of relationships among people, material artefacts and activities" (2009, 118). In this section I highlight ways in which interpersonal relationships participate in and 
shape practices and knowing. The activity of revising colleagues' translations is, for this translation department, an integral part of their practice of translating. Every translated text is printed and is read in hard copy by a colleague, with the source text in hard copy alongside it, using a ruler or a blank piece of paper as a guide to control their line-by-line reading and comparison and make sure they do not miss details. The reviser annotates the translation, in pencil. Anna, for example, uses one notation to flag up changes required and a different notation to indicate a suggestion or an issue for discussion. The revisers not only mark up the text but also note down their own suggestions or solutions.

When the reviser has completed this activity, she notifies her translator colleague and they find a time to meet to go through the corrections together. They sit together at a table in the translator's office, sharing a single, annotated hard copy, reading through the annotations, one by one, and discussing the rationale for them and the possible solutions proposed by the reviser. Observing these encounters makes clear how vital it is for the translators, as part of a very small team, to be careful and thorough in their revisions, thus being of maximum help to their colleagues, but also to be able to explain and justify their corrections and suggestions non-confrontationally and encouragingly, so that relations are not damaged through undue or harshly delivered criticism. Likewise, the translator being revised needs to know how to react constructively to errors being spotted or suggestions for improving their work.

Once this process is completed, the meeting draws to a close and the reviser returns to their office. At a convenient time, usually shortly after the meeting, the translator takes the annotated copy to her desk where she implements changes on her electronic version of the translation, using a document holder or guide to facilitate her progression through the physical document while editing on screen.

This depiction of revising activities adds to our inventory of embodied and materially mediated activities. However, it is also a useful example of the relational and emergent nature of knowing. By working separately and then combining their efforts, the translators believe that they improve the quality of their final translation output. From the perspective of knowing we can observe how new or changed understandings of the texts or new translation solutions emerge from this joint effort and discussion. The relational knowing enacted here is an instance, as defined by Nicolini $(2011,613)$, of "knowing with others and among others as well as knowing, to some extent, what others know".

\subsection{Interconnectedness of Practices and Knowings}

Nicolini $(2011,605)$ argues that an episode of knowing in practice is a locus in a broader field, with numerous connections to other knowings and practices both leading to it and radiating from it. A study of knowing in practice thus requires us to study the enactments of a specific practice but also "the texture of relationships that connects it to other practices" (ibid.). A detailed analysis of the texture of the relationships or the constellations of related practices is beyond the scope of this paper but even brief consideration of the accounts above reveals aspects of the interconnectedness enacted in the translators' and Diane's practices and knowings. 
One of the most salient relationships between practices and knowings in the translation industry is the one between the practice of managing translation projects and the practice of translating. In this RO, Diane's gatekeeping of clients, administrative processing of jobs and comprehensive record-keeping is central to the work organization of the translators. Without her work and the knowing she enacts, the translation practice would be different, and perhaps more difficult for the translators to perform. I observe how the translators manage to hold the fort when Diane is absent one afternoon, but this is far from a full-scale enactment of Diane's activities, and she then focuses on catching up on her own tasks the following day, which in turn enables the translators to focus fully on their translation practice. Diane's project management practice, in turn, is inextricably linked to and shaped by the translation practices enacted by her colleagues.

The other practice that is clearly interconnected with the practices of the translators in the RO is the practice of English-language editing of scientific papers. The RO's translating and editing assignments are commissioned, in institutional and procedural terms, in the same way as translations. They are processed and prepared by Diane for the translators in the same way; they figure on the rolling work schedule alongside translation assignments, labelled as editing and assigned to one person rather than a translator and reviser. When editing, the translators draw on their specialist knowledge of scientific domains and genres, just as they do in translating. It can be argued that the shared situatedness - the physical and temporal colocation of both practices in the RO, 'carried' by the same individuals and team - means that the two practices of translating and monolingual editing and their knowings are perhaps more similar at this site than might otherwise be expected when comparing practices of this kind.

\section{Conclusion}

This paper has adopted the position that all work, including the everyday work of translators, is knowledgeable. Moreover, knowledge is not synonymous with information or data, acquired through transmission in some encoded form from one individual's brain to another's. Rather, knowing is construed as dynamically situated and shared. In foregrounding practices, this account shows how translators, as human actors, are 'carriers' of practices but how those practices consist of and are shaped by emergent combinations of bodily activities and material arrangements. The practices are themselves a site of knowing; in other words, knowing transpires in and through the practices. Knowing, thus conceived, does not pre-exist the practice but rather emerges in the doings and sayings that constitute the practice. Since knowing emerges in and from practice, it necessarily involves human body and brain, as well as material objects. Knowing is both individually and collectively enacted, and is embedded in a specific site of practice.

In conceptualizing the relationship between knowing and practice in this way, this contribution has shown the potential offered by practice theory for enhanced understandings of the practice of translating. In analyzing aspects of the practices observed in a translation department, the paper has illustrated some dimensions of the emergent, embodied, materially mediated, collective knowings enacted in those practices. This practice-theoretical approach 
thus provides a valuable alternative to text-oriented or cognition-based studies of translation or knowledge, enabling us to account for the entanglements of human activities and material objects in enactments of translating. Finally, the focus on a translation department helps to widen the range of professional practices that are studied through a sociological lens; on several dimensions, research involving professional linguists can offer a desirable counterbalance to the professions and settings typically featured in social studies of workplaces and knowledge work.

\section{References}

Bain, Rod, and Christopher Mueller. 2016. 'Understanding Practice(s) and Practising'. In Knowledge and Practice in Business and Organisations, edited by Kevin Orr, Sandra Nutley, Shona Russell, Rod Bain, Bonnie Hacking, and Clare Moran, 30-42. London and New York: Routledge.

Blackler, Frank. 1995. 'Knowledge, Knowledge Work and Organizations: An Overview and Interpretation'. Organization Studies 16 (6): 1021-46. DOI:10.1177/017084069501600605.

Bräuchler, Birgit, and John Postill, eds. 2010. Theorising Media and Practice. New York and Oxford: Berghahn Books.

British Standards Institution. 2015. 'ISO 17100:2015 Translation Services - Requirements for Translation Services'. BSI Standards Limited.

Brown, Anna, Gail Greig, and Emilia Ferraro. 2016. 'Sensing Bodies: The Aesthetics of Knowing and Practising'. In Knowledge and Practice in Business and Organisations, edited by Kevin Orr, Sandra Nutley, Shona Russell, Rod Bain, Bonnie Hacking, and Clare Moran, 85-96. London and New York: Routledge.

Brown, John Seely, and Paul Duguid. 1991. 'Organizational Learning and Communities-ofPractice: Towards a Unified View of Working, Learning, and Innovation'. Organization Science 2 (1): 40-57. DOI: 10.1287/orsc.2.1.40.

Bourdieu, Pierre. 1977. Outline of a Theory of Practice, translated by Richard Nice. Cambridge: Cambridge University Press.

Bourdieu, Pierre. 1990. The Logic of Practice, translated by Richard Nice. Cambridge: Polity Press.

Buzelin, Hélène. 2006. 'Independent Publisher in the Networks of Translation'. TTR: Traduction, Terminologie, Rédaction 19 (1): 135-73. DOI: 10.7202/016663ar Buzelin, Hélène. 2007. 'Translations "in the Making"'. In Constructing a Sociology of Translation, edited by Michaela Wolf and Alexandra Fukari, 135-69. Amsterdam and Philadelphia: John Benjamins.

Caldwell, Raymond. 2012. 'Reclaiming Agency, Recovering Change? An Exploration of the Practice Theory of Theodore Schatzki'. Journal for the Theory of Social Behaviour 42 (3): 283-303. doi:10.1111/j.1468-5914.2012.00490.x.

Chesterman, Andrew, and Emma Wagner. 2002. Can Theory Help Translators? A Dialogue between the Ivory Tower and the Wordface. Manchester: St Jerome Publishing. 
Cook, Scott D. N., and John Seely Brown. 1999. 'Bridging Epistemologies: The Generative Dance Between Organizational Knowledge and Organizational Knowing'. Organization Science 10 (4): 381-400. DOI:10.1287/orsc.10.4.381.

Ehrensberger-Dow, Maureen. 2014. 'Challenges of Translation Process Research at the Workplace'. In Minding Translation, edited by Ricardo Muñoz Martín, 355-83. Alicante: Publicaciones de la Universidad de Alicante.

Ehrensberger-Dow, Maureen, and Sharon O'Brien. 2015. 'Ergonomics of the Translation Workplace: Potential for Cognitive Friction'. Translation Spaces 4 (1): 98-118. DOI:10.1075/ts.4.1.05ehr.

Hermans, Theo. 2007. The Conference of the Tongues. Manchester: St Jerome Publishing. Gherardi, Silvia. 2006. Organizational Knowledge: The Texture of Workplace Learning. Oxford: Blackwell.

Gherardi, Silvia. 2009. 'Introduction: The Critical Power of the "Practice Lens"'. Management Learning 40 (2): 115-28. DOI:10.1177/1350507608101225.

Giddens, Anthony. 1979. Central Problems in Social Theory: Action, Structure, and Contradiction in Social Analysis. Berkeley: University of California Press.

Giddens, Anthony. 1984. The Constitution of Society: Outline of the Theory of Structuration. Berkeley: University of California Press.

González-Davies, Maria, and Vanessa Enríquez-Raído. 2016. 'Situated Learning in Translator and Interpreter Training: Bridging Research and Good Practice'. The Interpreter and Translator Trainer 10 (1): 1-11. DOI:10.1080/1750399X.2016.1154339.

Hanna, Sameh. 2016. Bourdieu in Translation Studies: The Socio-Cultural Dynamics of Shakespeare Translation in Egypt. London and New York: Routledge.

Inghilleri, Moira, ed. 2005. The Translator, Special Issue: Bourdieu and the Sociology of Translation and Interpreting. Vol. 11(2).

Jonas, Michael, and Beate Littig, eds. 2017. Praxeological Political Analysis. London and New York: Routledge.

Kiraly, Don. 2000. A Social Constructivist Approach to Translator Education: Empowerment from Theory to Practice. Manchester: St Jerome Publishing.

Kiraly, Don. 2012. 'Growing a Project-Based Translation Pedagogy: A Fractal Perspective'. Meta 57 (1): 82-95. DOI:10.7202/1012742ar.

Lafeber, Anne. 2012. 'Translation Skills and Knowledge - Preliminary Findings of a Survey of Translators and Revisers Working at Inter-governmental Organizations'. Meta 57 (1): 108-131. DOI:10.7202/1012744ar.

Latour, Bruno. 2005. Reassembling the Social: An Introduction to Actor-Network-Theory. Oxford: Oxford University Press.

Lave, Jean, and Etienne Wenger. 1991. Situated Learning: Legitimate Peripheral Participation. Oxford: Oxford University Press.

LeBlanc, Matthieu. 2013. 'Translators on Translation Memory (TM): Results of an Ethnographic Study in Three Translation Services and Agencies'. Translation \& Interpreting 5 (2): 1-13. 
Nicolini, Davide. 2009. 'Zooming In and Out: Studying Practices by Switching Theoretical Lenses and Trailing Connections'. Organization Studies 30 (12): 1391-1418. DOI:10.1177/0170840609349875.

Nicolini, Davide. 2011. 'Practice as the Site of Knowing: Insights from the Field of Telemedicine'. Organization Science 22 (3): 602-20. DOI:10.1287/orsc.1100.0556.

Nicolini, Davide. 2012. Practice Theory, Work, and Organization: An Introduction. Oxford: Oxford University Press.

Nonaka, Ikujiro. 1994. 'A Dynamic Theory of Organizational Knowledge Creation'. Organization Science 5 (5): 14-37. DOI: 10.1287/orsc.5.1.14.

Nutley, Sandra, Rod Bain, Bonnie Hacking, Clare Moran, Kevin Orr, and Shona Russell. 2016. 'Introducing the Aims, Background and Content of This Book'. In Knowledge and Practice in Business and Organisations, edited by Kevin Orr, Sandra Nutley, Shona Russell, Rod Bain, Bonnie Hacking, and Clare Moran, London and New York: Routledge.

Olohan, Maeve, and Elena Davitti. 2015. 'Dynamics of Trusting in Translation Project Management: Leaps of Faith and Balancing Acts'. Journal of Contemporary Ethnography. Online first publication. DOI: 10.1177/0891241615603449.

Orlikowski, Wanda J. 2002. 'Knowing in Practice: Enacting a Collective Capability in Distributed Organizing'. Organization Science 13 (3): 249-73. DOI: $10.2307 / 3086020$.

Orr, Kevin, Sandra Nutley, Shona Russell, Rod Bain, Bonnie Hacking, and Clare Moran, eds. 2016. Knowledge and Practice in Business and Organisations. London and New York: Routledge.

PACTE . 2014. 'First Results of PACTE Group's Experimental Research on Translation Competence Acquisition: The Acquisition of Declarative Knowledge of Translation'. In Minding Translation, guest edited by Ricardo Muñoz Martín, MonTI Special Issue 1: 85-115. Alicante: Publicaciones de la Universidad de Alicante.

Parry, Richard. 2014. 'Episteme and Techne'. In The Stanford Encyclopedia of Philosophy, edited by Edward N. Zalta, Fall 2014. http://plato.stanford.edu/archives/fall2014/entries/episteme-techne/.

Polanyi, Michael. 1962. Personal Knowledge: Towards a Post-Critical Philosophy. Chicago: University of Chicago Press.

Polanyi, Michael. 1966. The Tacit Dimension. Chicago: University of Chicago Press.

Postill, John. 2010. 'Introduction: Theorising Media and Practice'. In Theorising Media and Practice, edited by Birgit Bräuchler and John Postill, 1-32. New York and Oxford: Berghahn Books.

Reckwitz, Andreas. 2002. 'Toward a Theory of Social Practices A Development in Culturalist Theorizing'. European Journal of Social Theory 5 (2): 243-63. DOI:10.1177/13684310222225432.

Reich, Ann, Donna Rooney, Anne Gardner, Keith Willey, David Boud, and Terry Fitzgerald. 2015. 'Engineers' Professional Learning: A Practice-Theory Perspective'. European Journal of Engineering Education 40 (4): 366-79.

DOI:10.1080/03043797.2014.967181. 
Rennstam, Jens, and Karen Lee Ashcraft. 2014. 'Knowing Work: Cultivating a PracticeBased Epistemology of Knowledge in Organization Studies'. Human Relations 67 (1): 3-25. DOI:10.1177/0018726713484182.

Risku, Hanna. 2009. Translationsmanagement: Interkulturelle Fachkommunikation Im Informationszeitalter. Tübingen: Gunter Narr.

Risku, Hanna. 2010. 'A Cognitive Scientific View on Technical Communication and Translation: Do Embodiment and Situatedness Really Make a Difference?' Target 22 (1): 94-111. DOI:10.1075/target.22.1.06ris.

Risku, Hanna. 2013. 'Knowledge Management and Translation'. In Handbook of Translation Studies : Volume 4, edited by Yves Gambier and Luc van Doorslaer, 92-97. Amsterdam: John Benjamins.

Risku, Hanna, Angela Dickinson, and Richard Pircher. 2010. 'Knowledge in Translation Studies and Translation Practice: Intellectual Capital in Modern Society'. In Why Translation Studies Matters, edited by Daniel Gile, Gyde Hansen, and Nike K. Pokorn, 83-94. Amsterdam: John Benjamins.

Risku, Hanna, Nicole Rossmanith, Andreas Reichelt, and Lukas Zenk. 2013. 'Translation in the Network Economy: A Follow-up Study'. In Tracks and Treks in Translation Studies: Selected Papers from the EST Congress, Leuven 2010, edited by Catherine Way, Sonia Vandepitte, Reine Meylaerts, and Magdalena Bartłomiejczyk, 29-49. John Benjamins Publishing.

Risku, Hanna, and Florian Windhager. 2013. 'Extended Translation: A Sociocognitive Research Agenda'. Target 25 (1): 33-45. DOI:10.1075/target.25.1.04ris.

Schatzki, Theodore R. 1996. Social Practices: A Wittgensteinian Approach to Human Activity and the Social. Cambridge: Cambridge University Press.

Schatzki, Theodore R. 2001. 'Introduction: Practice Theory'. In The Practice Turn in Contemporary Theory, edited by Theodore R. Schatzki, Karin Knorr-Cetina, and Eike von Savigny, 1-14. London and New York: Routledge.

Schatzki, Theodore R. 2002. The Site of the Social: A Philosophical Account of the Constitution of Social Life and Change. University Park, PA: Pennsylvania State University Press.

Schatzki, Theodore R. 2005. 'Peripheral Vision: The Sites of Organizations'. Organization Studies 26 (3): 465-84. DOI:10.1177/0170840605050876.

Schatzki, Theodore R., Karin Knorr-Cetina, and Eike von Savigny, eds. 2001. The Practice Turn in Contemporary Theory. London and New York: Routledge.

Shove, Elizabeth, Mika Pantzar, and Matt Watson. 2012. The Dynamics of Social Practice. London: Sage.

Thompson, Paul, Chris Warhurst, and George Callaghan. 2001. 'Ignorant Theory and Knowledgeable Workers: Interrogating the Connections between Knowledge, Skills and Services'. Journal of Management Studies 38 (7): 923-42. DOI:10.1111/14676486.00266.

Tooman, Tricia, Cinla Akinci, and Sandra Davies. 2016. 'Understanding Knowledge and Knowing'. In Knowledge and Practice in Business and Organisations, edited by Kevin Orr, Sandra Nutley, Shona Russell, Rod Bain, Bonnie Hacking, and Clare Moran, 17-29. London and New York: Routledge. 
Tsoukas, Haridimos. 1996. 'The Firm as a Distributed Knowledge System: A Constructionist Approach'. Strategic Management Journal 17: 11-25. DOI: 10.1002/smj.4250171104.

Tsoukas, Haridimos. 2005. Complex Knowledge: Studies in Organizational Epistemology. Oxford University Press.

Tyulenev, Sergey. 2012. Applying Luhmann to Translation Studies: Translation in Society. London and New York: Routledge.

van Rooyen, Marlie. 2013. 'Structure and Agency in News Translation: An Application of Anthony Giddens' Structuration Theory'. Southern African Linguistics and Applied Language Studies 31 (4): 495-506. DOI:10.2989/16073614.2013.864445.

Warde, Alan. 2005. 'Consumption and Theories of Practice'. Journal of Consumer Culture 5 (2): 131-53. DOI:10.1177/1469540505053090.

Warde, Alan. 2016. The Practice of Eating. Cambridge: Polity Press. 